\title{
Can Group Discussions And Individualized Assignments Help More Students Succeed In Developmental Mathematics?
}

\author{
Reem Jaafar, Ph.D., LaGuardia Community College, C.U.N.Y., USA
}

\begin{abstract}
Students taking developmental mathematics courses resist attempting word problems when they are presented to them. Although word problems can help students contextualize learning, develop better understanding of the concepts and apply world knowledge, they constitute an impediment to students' progress in developmental mathematics courses. A two-semester study on the first developmental mathematics course at LaGuardia Community College shows that students perform better at word problems when they have been discussed in groups with their peers prior to the homework. Moreover, when assigned word problems without a class discussion, students perform better when these problems are individualized based on their areas of interest.
\end{abstract}

Keywords: Group Discussion; Word Problems; Developmental Mathematics

\section{INTRODUCTION}

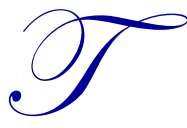

here is an urgent need in the United States to develop mathematics literacy. A recent study done on U.S. students of the high school graduating class of 2011 concluded that the U.S. has a $32 \%$ proficiency rate in mathematics compared with $44 \%$ for Germany and 58\% for Korea (Peterson, Woessmann, Hanushek, \& Lastra-Anadón, 2011). In the United States, 45\% of all undergraduate students are enrolled in public 2-year colleges. A Community College Research Center study of over 250,000 students at 57 community colleges found that $59 \%$ of entering students were placed in developmental mathematics (Bailey, Jeong, \& Cho, 2010).

In this paper I present a study assessing whether students become better at solving word problems if their context was of interest to them, and if discussed in groups in a developmental mathematics course. The students' particular area of interest is determined through a survey given at the beginning of the semester. At the same time, a structured student-centered approach using group discussion has been adopted for lessons that involve word problems. The study shows that familiarity, group discussions and individual interest had a positive impact on students' handling of word problems and their ability to solve them.

\section{WHY FOCUS ON DEVELOPMENTAL MATHEMATICS, AND WHAT IS THE IMPORTANCE OF WORD PROBLEMS IN THESE COURSES?}

\section{Developmental Mathematics at LaGuardia \& Nationwide}

The nationwide low proficiency rate in mathematics reflects the crisis in developmental mathematics education. The President of the Carnegie Foundation for the Advancement of Teaching S. Bryk once stated "Developmental mathematics courses represent the graveyard of dreams and aspirations" (Merseth, 2011, p. 32). Improving passing rates in these at-risk courses is a major focus of the research on developmental education. Several studies focused on the course design and the relationship between course length and course success (Sheldon \& Durdella, 2010; Squires, Faulkner, \& Hite, 2009; Vasquez Mireles, Offer, Ward, \& Dochen, 2011). Other studies acknowledged that course redesign is not sufficient. For example, after examining challenges and recent initiatives 
in developmental mathematics, Bonham and Boylan (2011) recommended the use of technology as a supplement to classroom instruction, and discussed some teaching techniques that were used to improve retention and passing rates. Nationwide, there have been initiatives such as Project Quantway and Statway, undertaken by the Carnegie Foundation, that targeted students at grave risk of failure in mathematics courses at the community college level (Merseth, 2011).

At LaGuardia Community College, we offer a series of two developmental mathematics courses. Typically in a given semester $41 \%$ of the incoming freshmen place in the first developmental course, and $29 \%$ place in the second course (LaGuardia Community College Institutional Research and Assessment, n.d.). Our overall passing rates for both developmental classes have been only $54 \%$ and reflect our nation's struggle with developmental education. On the other hand, the passing rates for credit-bearing college mathematics courses range from $70 \%$ to $90 \%$.

The first developmental mathematics course covers a wide range of topics with a list of learning goals (see

Appendix A). One of these goals is to "solve real life problems requiring a full range of arithmetic skills." From my classroom experience, I noticed that this particular goal is not met. For example, my students' first reaction to basic word problems early and late during the semester has been "Should I multiply or divide?" or "Should I add or subtract?" This reveals a deeper problem. Were students previously taught procedural knowledge at the expense of conceptual knowledge? Many students do not recognize that there are concepts underlying mathematical procedures (Oaks 1987/1988, 1990). Meanwhile, research has supported that students' beliefs about mathematics can influence their success in upper-level mathematics courses (Harel \& Sowder, 1998). Both procedural ability and conceptual understanding are essential for students' success (Hiebert \& Carpenter, 1992) and so if students were exposed to the conceptual ideas of division and multiplication, not to the algorithm only, they may not have asked whether they need to multiply or divide. This attitude was supported by a survey given to students in developmental mathematics at the beginning of every semester asking them to describe "word problems." The word "confusing" was consistently the most frequently used expression.

\section{Benefits of Word Problems}

For the purpose of this study a word problem was defined as a mathematical exercise expressed as a hypothetical situation explained in words (Oxford University Press, 2015). The benefits of developing skills to tackle word problems are not limited to the conceptual and procedural knowledge. They can also help students contextualize learning and transfer their knowledge. Word problems in a developmental mathematics course are encountered in various parts of the course: at the beginning with single-step arithmetic procedures, in the middle with least common multiples, and towards the end with fractions, percentages and multi-step problems. Students must understand the conceptual ideas behind word problems early on to be able to tackle the later problems that combine multi-step procedures and the use of several concepts encountered during the semester. Staub and Reusser (1995) summarized the benefits of word problems as

Because word problems have a clear final processing goal and because a successful solution largely depends on thoroughly understanding the situations denoted in a text, these problems provide excellent opportunities to explicitly apply world knowledge, discourse and language knowledge, as well as arithmetic knowledge. (p. 302)

Reusser and Stebler (1997) also thought that word problems are important because they provide an opportunity to study the interplay among and between language processes, mathematical processes and situational reasoning. They conducted a research study that was an extension of Verschaffel, De Corte and Lasure's (1994) experiment where fifth grade students were given sets of problems that contained some unrealistic situations. The results of the experiments showed that students solved a significant number of the unsolvable problems without thinking about whether the situation presented was realistic or not. Although most of the research about word problems has involved elementary-level school students, Reusser and Stebler (1997) extended their research to older secondary school students. Their results showed that the average level of "unrealistic reactions" (p. 322) remained remarkably high and that even explicit warnings did not increase students' realistic behavior. To solve this issue, Greer (1997) suggested an alternative conceptualization of word problems where students could use real-world knowledge data while solving them. 
Other studies investigated students' perception of word problems. In their book, Verschaffel, Greer, and De Corte (2000) reported findings from diverse research projects in several countries in elementary algebra and concluded that students perceived word problems as artificial and as having to be solved algorithmically using a certain operations without connecting it to any particular context. When studying in detail the connection between students' solution to word problems and the context of the problems themselves, they noted that students tended to exclude real world knowledge while solving the problems. While some viewed the process of solving word problems as a progression of translating words into mathematical expression and then solving them, Verschaffel et al. (2000) thought that this was a "closed" approach (p. 178) in which students were simply constrained to use a mathematical operation and the information given could lead them to the "suspension of sense making" (p. 3). On a similar note, Barwell (2005a, 2005b), agreed that students treated word problems "too realistically" (Barwell, 2011, p. 1) and studied issues with word problems from a slightly linguistic angle. He suggested having students write their own problems (Barwell, 2001). This idea was also suggested by Winograd and Higgins (1994-1995).

Regarding individual interest, Renninger, Ewen, and Lasher (2002) detailed the performance of three 11 year-old students on contextualizing assignments in expository texts and word problems. The mathematics sheet contained 12 problems that varied in difficulty and interest. They found that on one hand, contexts appeared to enable students to focus on meaning and focus on the task, but on the other hand contexts could lead weaker students to assume that they had worked out a problem correctly when they had not. Research has also shown that in order to solve a word problem successfully, it has to be understood in its context and students can create shared contextualization for understanding a particular word problem when working in groups (Wyndham \& Säljö, 1997). In that case, they made realistic considerations and successfully understood the problem presented. I adopted this model in my classroom. In my study, the assignments that predominantly contained word problems were discussed in groups. This approach directed students to help each other and prevented many situations of "suspension of sense making"((Verschaffel et al., 2000, p. 3). Students were also given individualized word problems with context of interest to them. The research methodology is detailed in the next section of this article.

\section{RESEARCH METHODOLOGY}

\section{Prestudy}

In order to explore students' perception of difficulty, a prestudy was conducted one semester prior to the actual study with 25 participants who took the first developmental mathematics course by placement. It consisted of a survey given at the beginning of the semester asking students to describe word problems, whether they have encountered them before, how they perceive the level of difficulty of word problems, and what their particular areas of interest were. It also included a questionnaire with a set of 29 problems to score by level of difficulty using a Likert scale of 1 to 5 , with 5 being the most difficult. Students handed in the survey and the questionnaire the first week of the semester. At the end of the semester, they were asked to rescore the problems on the questionnaire. The survey helped assess students' attitude and prior experience with word problems by looking at terms used to describe them. The questionnaire consisted of 29 problems that students were going to encounter during the semester. The skills needed to solve these problems varied from a single-step multiplication, division, addition, or subtraction to multi-step problems that involved decimals, percentages and setting proportions. The questionnaire helped determine how students' perception of difficulty of the problems evolved by comparing changes in the percentage of students who scored word problems at a certain level of difficulty between the beginning and the end of the semester.

The survey results showed that word problems are confusing to students. In fact, three students in the survey answered that they hated word problems because they did not know whether they needed to "multiply or divide." Others claimed that they hated word problems because they are "confusing" and "time-consuming." Some students responded that they "hate math." The questionnaire revealed that more students found the problems easier at the end of the semester. At the beginning of the semester, 19\% of students gave the problems a scoring of 1 and $14.5 \%$ a scoring of 5, compared with $33 \%$ and $6 \%$ respectively at the end of the semester. This was expected because many of the problems had already been encountered in class and students became familiar with them. 


\section{Study}

\section{Participants}

This study involved 26 participants who took the first developmental mathematics course by placement the semester following the prestudy. Data from the college's Institutional Research Office revealed that $32 \%$ of the students enrolled in this section of the class were Hispanic, 39\% were Black, $4 \%$ were Asian, $11 \%$ were White, and $14 \%$ reported other race or ethnicity. The class had a predominantly female population (68\%). Only $14 \%$ of the students were repeaters compared with $52 \%$ in the previous semester. Half (50\%) of the students had a cumulative GPA of 2.0 or higher.

Design

The study consisted of several steps. First, I asked students to complete the same survey given during the prestudy to assess their attitude toward word problems. However, for this study, I did not administer the questionnaire with the 29 problems. Based on students' answers to their particular area of interest, I assigned a series of five written homework problems alternating between general and targeted problems by interest. Students turned them in without any prior class discussion or hint. In addition to those written problems, students were assigned online homework using a platform common to all developmental mathematics sections. Typically students were expected to complete three online homework assignments per week. Of the 40 online homework assignments, 7 contained predominantly word problems. These homework assignments were labeled as lessons 1 through 7 for purposes of this research. In order to provide an appropriate pedagogy in the classroom every time the lesson consisted of word problems, I gave the online homework problems as a handout to students in class and I asked them to score the level of difficulty of each problem on a scale of 1 to 5 based just on reading them without attempting to solve them. Then I asked students to discuss each problem in groups of four or five and after a joint class discussion, I asked them again to rescore the level of difficulty of each one. Appendix B provides a sample of those problems. In general research has shown that cooperative learning can play a positive role in increasing students' problem-solving ability in college developmental courses (Dees, 1991). Although the pedagogy did not incorporate the full aspects of cooperative learning, I expected group discussions to yield similar benefits.

\section{Procedure}

After obtaining the approval of the Institution's Review Board, surveys were conducted during the first week of the semester where students were asked about their particular areas of interest. Based on the survey results, during the course of the semester students were given five sets of written word problems designed by the instructor. Three sets $(1,3$, and 5) had general word problems and two sets (2 and 4) had word problems targeted by interest. Appendix C lists samples of the general and the targeted word problems.

When explaining lessons 1 through 7, I carefully selected the groups to maximize peer interaction. Each group contained students with different mathematics achievement levels and at least one student who could properly communicate the solution to peers. Students were given seven handouts across the semester. The topics and skills covered in the homework varied: the early homework included single-step multiplication, division, addition, or subtraction, whereas the later ones included setting proportions, more sophisticated multi-step processes that included calculating quantities in different contexts using proportions and percentages, and using percentages to calculate discount amount and final prices. The more difficult problems came later in the semester (homework 5 through 7) whereas the easier ones (1 through 4) came earlier. After holding group discussions when explaining lessons 1 through 7, students were expected to complete identical problems as part of their online assignment

\section{Measures}

The survey helped assess students' attitudes and prior experience with word problems by looking at terms used to describe them. The scoring of the level of difficulty of the word problems before and after class discussion was analyzed. The written homework problems, alternating between targeted and general, helped create individualized assignments and determine whether students were better at solving word problems if they were 
related to a topic of interest to them. Comparing the grades of the targeted versus the general written homework helped determine students' problem solving ability when unfamiliar but interesting problems were presented to them. Students' scores on the online homework were compared to scores of students attending other sections and to scores of other students who previously took my course. Students' scores on the online homework were also compared to their scores on the written problems (targeted and general combined). Thus, the study consisted of two interventions: (a) five written homework problems alternating between general and targeted by interest without prior class discussion, and (b) seven online homework problems following a class discussion in groups.

\section{RESULTS}

\section{General}

In order to describe word problems in the initial survey, students used similar words to the ones used the previous semester, such as "confusing" and "tricky." In the same survey, 30\% of students expressed interest in health topics, $22 \%$ expressed interest in sports and baseball, and $48 \%$ expressed interest in money and finance. These were the only choices given to students, in addition to students' having the option to choose "other/something else".

Students were asked to rate the level of like or dislike of word problems on a scale of 1 to 5 (where 1 means a strong dislike): $22 \%$ gave them a rating of 1 or 2 which indicates a dislike to a strong dislike, $52 \%$ gave them a rating of 3 and $26 \%$ gave them a rating of 4 or 5 .

When asked to describe word problems, 55\% of students used the word "confusing" or "confused", while $18 \%$ of students used the word "complicated" or "hard". The rest described them as "fun" (18\%) or "tricky" (9\%).

\section{Group Discussion and Online Assignments}

Table 1 provides a summary that contains the average ranking for each category for lessons 1 through 7 .

Figure 1 shows how the students' scoring of the level of difficult evolved during the semester. It reveals that the percent of students who found the problems at a higher level of difficulty peaked for the third lesson and began dropping after the fourth lesson (and reached $0 \%$ by lesson 7) and that on average $36.5 \%$ of students found the problems at a lower level of difficulty after participating in discussion.

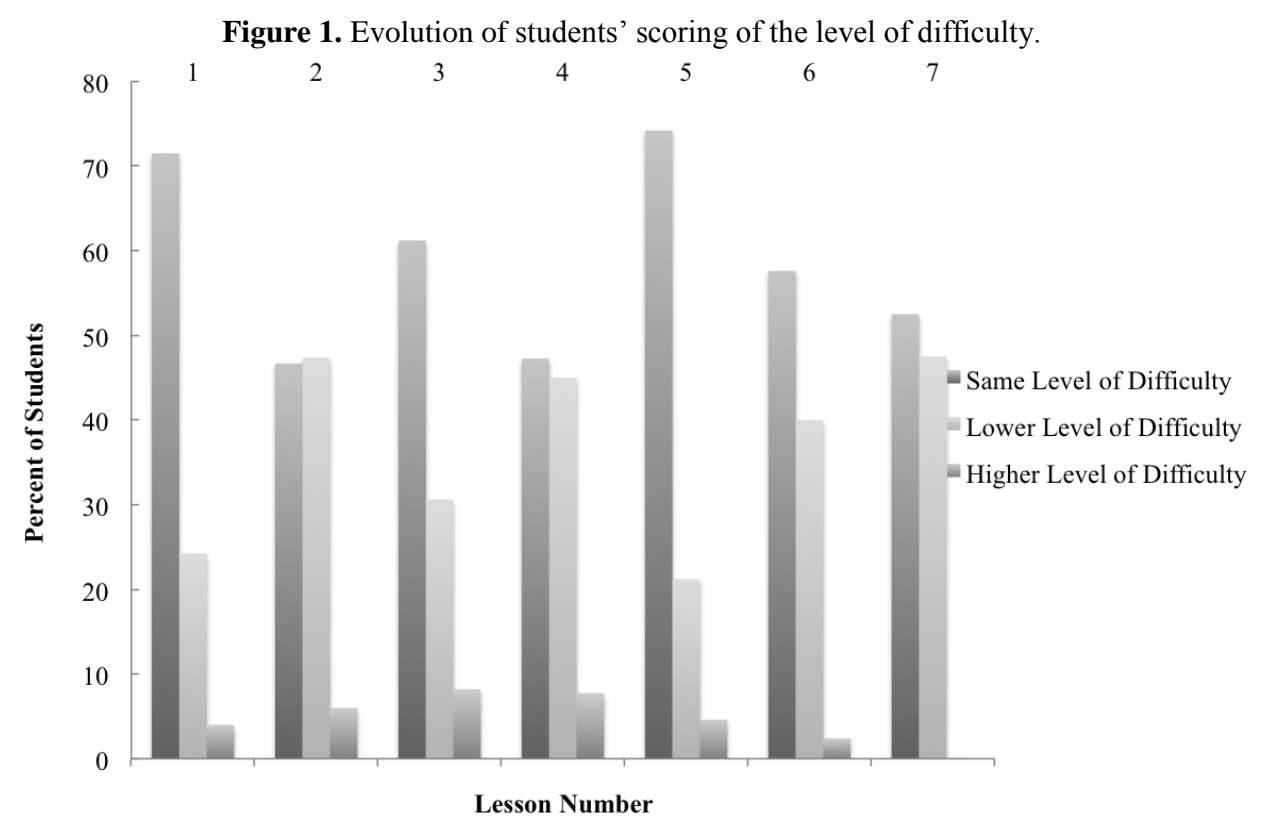


Table 1. Change in the Perception of Difficulty

Percent of Students who Ranked the Problems at the Same, Lower or Higher Level of Difficulty ${ }^{1}$

\begin{tabular}{lccrrrrrr}
\multicolumn{1}{c}{ Lesson } & $\mathbf{1}$ & $\mathbf{2}$ & $\mathbf{3}$ & $\mathbf{4}$ & $\mathbf{5}$ & $\mathbf{6}$ & $\mathbf{7}$ \\
\hline Same Level & 71.75 & 46.67 & 61.02 & 47.25 & 74.20 & 57.60 & 52.50 \\
Lower Level & 24.25 & 47.33 & 30.60 & 45.00 & 21.20 & 40.00 & 47.50 \\
Higher Level & 4 & 6 & 8.20 & 7.75 & 4.60 & 2.40 & 0 \\
Class Average & 100 & 83.51 & 96.19 & 92.17 & 85.45 & 84.37 & 83.33
\end{tabular}

On The Online

Homework

${ }^{1}$ Note: The perception of difficulty is collected for every problem (before and after discussion). A final average is given for each of the seven lessons discussed in class.

Table 2 provides a comparison of students' scores on the same homework (lessons 1 through 7) of my section and scores of all students taking the same course. It shows students' scores in my section were higher than the average scores of all students taking the class except for the homework on lessons 2 and 6 where the scores were comparable. This finding indicates that having students work problems in group may have helped them become better problem solvers. Prior to the study, my classroom average was consistent with the general average for all students who typically attempt the homework during a particular semester (see last row of table 2). However, when the intervention was implemented, my class average for homework assignments 1 and $3-7$ became $1 \%$ to $12 \%$ higher than the general average for all developmental sections.

Table 2. Comparison of Students' Online Scores on the Online Homework (or Lesson)

\begin{tabular}{lccccccc}
\hline \multicolumn{1}{c}{ Online score } & Lesson 1 & $\mathbf{2}$ & $\mathbf{3}$ & $\mathbf{4}$ & $\mathbf{5}$ & $\mathbf{6}$ & $\mathbf{7}$ \\
\hline Section of the & $\mathbf{1 0 0}$ & $\mathbf{8 3 . 5 1}$ & $\mathbf{9 6 . 1 9}$ & $\mathbf{9 2 . 1 7}$ & $\mathbf{8 5 . 4 5}$ & $\mathbf{8 4 . 3 7}$ & $\mathbf{8 3 . 3 3}$ \\
Study & $\mathrm{N}=26$ & $\mathrm{~N}=26$ & $\mathrm{~N}=21$ & $\mathrm{~N}=23$ & $\mathrm{~N}=22$ & $\mathrm{~N}=16$ & $\mathrm{~N}=20$ \\
\hline All Sections & $\mathbf{9 5 . 6 8}$ & $\mathbf{8 5 . 3 9}$ & $\mathbf{8 7 . 4 7}$ & $\mathbf{8 2 . 7 0}$ & $\mathbf{8 1 . 5 3}$ & $\mathbf{8 3 . 4 0}$ & $\mathbf{7 5 . 8 4}$ \\
& $\mathrm{N}=1054$ & $\mathrm{~N}=1059$ & $\mathrm{~N}=991$ & $\mathrm{~N}=875$ & $\mathrm{~N}=733$ & $\mathrm{~N}=756$ & $\mathrm{~N}=617$ \\
\hline
\end{tabular}

\section{Targeted (T) Versus General (G) Written Word Problems}

The results and the setting of the general $(\mathrm{G})$ and the targeted $(\mathrm{T})$ word problems that were given in writing are presented in Table 3. The general written homework sets and the online homework contain problems of the same level of difficulty. Students performed better on the problems targeted by interest.

Table 3. The Class Average for the General (G) and the Targeted (T) Word Problems Homework

\begin{tabular}{cllccc}
\hline & HW 1(G) & HW 2(T) & HW 3(G) & HW 4(T) & HW 5(G) \\
\hline $\begin{array}{c}\text { Average Class } \\
\text { Score }\end{array}$ & 63.52 & 85.83 & 52.32 & 69.75 & 66.76 \\
\hline \multirow{2}{*}{ Time Frame } & $\begin{array}{l}\text { Early in the } \\
\text { semester around } \\
\text { the same time as } \\
\text { Lesson 1 online } \\
\text { homework }\end{array}$ & $\begin{array}{l}\text { Around the same } \\
\text { time as lesson 3 } \\
\text { online homework }\end{array}$ & $\begin{array}{l}\text { Around the same } \\
\text { time as Lesson 5 } \\
\text { online homework }\end{array}$ & $\begin{array}{l}\text { Towards the end, } \\
\text { around the time of } \\
\text { Lesson 6 online } \\
\text { homework }\end{array}$ & $\begin{array}{l}\text { At the end of the } \\
\text { semester, after } \\
\text { Lesson 7 online } \\
\text { homework }\end{array}$ \\
\hline
\end{tabular}

I invested time when giving feedback to students on their targeted problems. After grading and returning the homework, I divided the class into three groups by area of interest and assigned a student leader to each group. The role of the leaders was to discuss the problems with their peers and help them correct their mistakes. I noticed that the students who successfully explained the problem to their peers tended to use world knowledge to communicate their ideas. In each group two or three students asked the leader specific questions. It is important to use the classroom to forge collaborations and study relationships among students. 


\section{INTERPRETATION OF THE RESULTS \& OPEN QUESTIONS}

The data presented in Table 1 of the scoring of the level of difficulty before and after discussion raise some interesting questions. A large percentage of students (average of 59\% for the 7 lessons) did not change their perception of the level of difficulty of the problems and yet over $80 \%$ of them answered the question correctly on the homework. Thus, one should draw a distinction between perception of difficulty and student confidence and ability. Students might have perceived some problems as difficult, but once the problems became familiar to them, they were able to solve them on the online homework. It could also be that the process of solving the problems may not have made them easier, but students might have become better at handling difficulty after the group discussions. The Discussion may also played a role in improving students' performance, as indicated by the data from Table 2. A comparison of the data from Table 2 with the data from Table 3 shows that students did better in general on the online homework after they discussed similar problems in class with their peers. Another benefit of group discussion was that I noticed anecdotally that several students developed study relationships outside of the classroom. They started attending office hours in groups. A comparison of the written homework (Table 3) shows that the average scores of the targeted problem sets were substantially higher than the average scores of the general sets (78 compared with 61). This finding may indicate that for at-risk students, one needs to pay attention to the context of the word problems. Word problems with contexts of interest to students can enhance motivation in developmental mathematics.

\section{LIMITATIONS}

This study was limited to a section of developmental mathematics each semester for two semesters. The sample can be expanded if the instructor teaches more than one section at a given semester. The college is moving towards accelerated courses in developmental mathematics, a course that combines Algebra with College Algebra, and a natural expansion of the study would be to include students in these courses.

I also was not able to understand how students handled problems they perceived as difficult. In the future, I plan to ask students to write a detailed explanation about their scoring of the level of difficulty of the problems before and after group discussion.

In my study, guided group discussions coupled with classroom instruction and individualized assignments engaged students throughout the semester. One can use this philosophy to expand on this study for a deeper insight into students' learning processes. For example, one can use the scoring by level of difficulty in conjunction with ability to solve problems and measures of confidence in order to assess the existence of any correlation between perception of difficulty and ability to solve a given problem. One can also incorporate writing in conjunction with areas of interest where students are asked to create their own word problems based on their areas of interest. This can help students relate procedural and conceptual knowledge, motivate them to work on word problems and help them relate classroom and world knowledge.

\section{CONCLUSION}

There is a measurable benefit to let students collaborate in developmental mathematics and to design problems targeted to students' interest. Students performed better on the word problems targeted by interest. These problems might be a step forward towards helping students to look at this world with a mathematical eye. I hope that student collaboration moves us a step forward towards transforming developmental mathematics from the "graveyard of dreams and aspirations" (Merseth, 2011, p. 32) to the gateway to students' ambitions and endeavors. In order to increase passing rates in developmental mathematics courses, a redesign of course content is not enough. At this point, it is crucial to continue the discussion on classroom instruction in order to help guide a greater number of students on their way to success. 


\section{ACKNOWLEDGEMENTS}

Dr. Jaafar would like to thank the leaders of the Carnegie Seminar facilitated by LaGuardia's Center of Teaching and Learning, Michele Piso, Patricia Sokolski, \& Dionne Miller for supporting her research and for providing feedback. She is also grateful to the leaders of the Faculty Scholarship and Publication Workshop Patricia Sokolski and Nancy Berke for their helpful suggestions on the final version of the manuscript.

\section{AUTHOR INFORMATION}

Reem Jaafar, PhD, CUNY Graduate School (Theoretical Physics 2010). In 2010, she joined the Mathematics, Engineering, and Computer Science Department at LaGuardia Community College as an assistant professor and became associate professor in 2013. She is the recipient of four grants, cofounded the Math Society, trains students regularly to compete in mathematics competitions, organizes STEM talks and supervises undergraduate student researchers. She conducts pedagogical research about effective classroom practices in mathematics education. In 2014, she became the coordinator of the Academic Peer Instruction Program. She has coauthored 13 papers in peerreviewed journals and has presented her research at over 14 conferences. E-mail: rjaafar@lagcc.cuny.edu

\section{REFERENCES}

Bailey, T., Jeong, D. W., \& Cho, S. W. (2010). Referral, enrollment, and completion in developmental education sequences in community colleges. Economics of Education Review, 29(2), 255-270.

Barwell, R. (2001). Difficulties with mathematical word problems. Proceedings of the British Society for Research Into Learning Mathematics, 21(2). Retrieved from http://www.bsrlm.org.uk/IPs/ip21-2/BSRLM-IP-21-211.pdf

Barwell, R. (2005a). Working on arithmetic word problems when English is an additional language. British Educational Research Journal, 31, 329-348.

Barwell, R. (2005b). Integrating language and content: Issues from the mathematics classroom. Linguistics and Education, 16, 205-218.

Barwell, R. (2011). Word Problems: Connecting language, life and mathematics. Retrieved from http://www.edu.gov.on.ca/eng/literacynumeracy/inspire/research/WW_Word_Problems.pdf

Bonham, B., \& Boylan, H. (2011). Developmental mathematics: Challenges, promising practices, and recent initiatives. Journal of Developmental Education, 34(3), 2-10.

Dees, R. L. (1991). The role of cooperative learning in increasing problem-solving ability in a college developmental math course. Journal for Research in Mathematics Education, 22(5), 409-421.

Greer, B. (1997). Modeling reality in mathematics classrooms: The case of word problems. Learning and Instruction, 7(4), 293-307.

Harel, G., \&Sowder, L. (1998). Students' proof schemes: Results from exploratory studies. In A. H. Schoenfeld, J. Kaput, \& E. Dubinsky (Eds), Research in collegiate mathematics education III, American Mathematical Society (pp. 234-283). Providence, RI: American Mathematical SocietyHiebert, J., \& Carpenter, T. (1992). Learning and teaching with understanding. In D. Grouws (Ed.), Handbook of research on mathematics teaching and learning (pp. 65-97). New York, NY: Macmillan.

LaGuardia Community College Office of Institutional Research and Assessment. (n.d.).Welcome to LaGuardia facts and figures, New York, NY: Author. Retrieved from http://www.lagcc.cuny.edu/IR/IR-facts/

Merseth, K. K. (2011). Update: Report on innovations in developmental mathematics-Moving mathematical graveyards. Journal of Developmental Education, 34(3), 32-39.

Oaks, A. B. (1988). The effects of the interaction of conception of mathematics and affective constructs on college students in developmental mathematics. Doctoral dissertation, University of Rochester (1987). Dissertation Abstracts International, 49, 54A.

Oaks, A. B. (1990, November). Writing to learn mathematics: Why do we need it and how can it help us? Paper presented at Association of Mathematics Teachers of New York State Conference, Ellenville, NY.

Oxford University Press. (2015). Definition of word problem in English. Retrieved from http://oxforddictionaries.com/us/definition/american_english/word-problem

Peterson, P. E., Woessmann, L., Hanushek, E. A., \& Lastra-Anadón, C. X. (2011). Globally challenged: Are U.S. students ready to compete? Retrieved from www.hks.harvard.edu/pepg/PDF/.../PEPG1103_GloballyChallenged.pdf 
Renninger, K. A., Ewen, L., \& Lasher, A. K. (2002). Individual interest in expository text and mathematical word problems. Learning and Instruction, 12(4), 467-490.

Reusser, K., \& Stebler, R. (1997). Every word problem has a solution-The social rationality of mathematical modeling in schools. Learning and Instruction, 7(4), 309-327.

Sheldon, C., \& Durdella, N. (2010). Success rates for students taking compressed and regular length developmental courses in the community college. Community College Journal of Research and Practice, 34, 39-54.

Squires, J., Faulkner, J., \& Hite, C. (2009). Do the math: Course redesign's impact on learning and scheduling. Community College Journal of Research and Practice, 33(11), 883-886.

Staub F. C., \& Reusser, K. (1995). The role of presentational structures in understanding and solving mathematical word problems. In C. A. Weaver S. Mannes, \& C. R. Fletcher (Eds.), Discourse comprehension. Essays in honor of Walter Kintsch (pp. 285-305). Hillsdale, NJ: Erlbaum.

Vasquez Mireles, S., Offer, J., Ward, D. D., \& Dochen, W. (2011). Incorporating study strategies in developmental mathematics/college algebra. Journal of Developmental Education, 34(3), 12-20.

Verschaffel, L., De Corte, E., \& Lasure, S. (1994). Realistic considerations in mathematical modeling of school arithmetic word problems. Learning and Instruction, 22(4), 273-294.

Verschaffel, L., Greer, B., \& De Corte, E. (2000). Making sense of word problems. Lisse, The Netherlands: Swets \& Zeitlinger.

Winograd, K., \& Higgins, K. (1994-1995). Writing, reading, and talking about mathematics: One interdisciplinary possibility. The Reading Teacher, 48(4), 310-318.

Wyndhamn, J., \& Säljö, R. (1997). Word problems and mathematical reasoning: A study of children's mastery of reference and meaning in textual realities. Learning and Instruction, 7(4), 361-382. 
APPENDIX A: LAGUARDIA COMMUNITY COLLEGE FIRST DEVELOPMENTAL MATH COURSE OBJECTIVES.

1. Solve real life problems requiring a full range of arithmetic skills.

2. Solve challenging real life problems involving ratios, proportion and percents.

3. Perform estimates, and judge whether more elaborate and precisely calculated solutions to problems are numerically reasonable.

4. Make calculations with signed numbers in a variety of different settings.

5. Compute areas and perimeters of basic two-dimensional geometric figures, and to use the Pythagorean Theorem to find the length of the third side of a right triangle given the lengths of two other sides.

6. Appreciate elementary numerical/algebraic relationships between two variables and to understand how such relationships can be visualized as planar graphs.

7. Solve elementary equations in both one and two variables as well as linear inequalities.

8. Understand/master algebra fundamentals as generalizations of arithmetic, establishing a base upon which to build the sequel course, MAT096. 


\section{APPENDIX B: SAMPLE PROBLEMS WORKED ON DURING CLASS DISCUSSIONS}

Questions 1 and 2 are part of the second online homework that contain word problems, questions 3 and 4 are part of the sixth online homework and problems 5,6 and 7 are part of the seventh (and final) online homework.

1. Find the LCM of 150, 200, 450 and 600 .

Before solving the problem, rank how difficult do you think it is: (1 being very easy, 5 very hard)

$\begin{array}{lllll}1 & 2 & 3 & 4 & 5\end{array}$

After solving and discussing the problem in class (with the professor and my peer), rank how difficult you find it.
1
2
3
4
5

2. Candies are packed in four different sized packets containing 150, 200, 450 or 600 candies respectively.

a) Find the smallest number of candies needed to make an exact number of packets of each size.

b) Find the number of packets of each kind that will be made from each particular number.

Before solving the problem, rank how difficult do you think it is: (1 being very easy, 5 very hard)

$\begin{array}{lllll}1 & 2 & 3 & 4 & 5\end{array}$

After solving and discussing the problem in class (with the professor and my peer), rank how difficult you find it.
1
2
3
4
5

3. On a map, 1 inch represents 2.7 miles. The distance on the map between two cities is 5.13 inches. How many miles apart are the cities?

Before solving the problem, rank how difficult do you think it is: (1 being very easy, 5 very hard)
1
2
3
$4 \quad 5$

After solving and discussing the problem in class (with the professor and my peer), rank how difficult you find it.
1
2
3
4
5

4. Twenty-six ounces of liquid dish soap cost $\$ 1.81$, while 28 ounces cost $\$ 1.98$ and the 30 ounces cost \$2.16. Which bottle of liquid dish soap is the best buy?

Before solving the problem, rank how difficult do you think it is: (1 being very easy, 5 very hard)
1
2
3
4
5

After solving and discussing the problem in class (with the professor and my peer), rank how difficult you find it.
1
2
3
4
5

5. Marilyn saves $34 \%$ of her income. Is she saves $\$ 680$ per month, find her monthly income.

$\underline{\text { Before }}$ solving the problem, rank how difficult do you think it is: (1 being very easy, 5 very hard)
1
2
3
4

5

After solving and discussing the problem in class (with the professor and my peer), rank how difficult you find it. 
6. Mr Smith earned $\$ 15000$ last year. His total deductions amount to $24 \%$ of his earnings. What was his take-home salary?

Before solving the problem, rank how difficult do you think it is: (1 being very easy, 5 very hard)

$\begin{array}{lllll}1 & 2 & 3 & 4 & 5\end{array}$

After solving and discussing the problem in class (with the professor and my peer), rank how difficult you find it.

$\begin{array}{lllll}1 & 2 & 3 & 4 & 5\end{array}$

7. The value of a new automobile depreciates $13 \%$ during the first year, and $14 \%$ during the second year. What is its depreciated value at the end of the second year if its original price was $\$ 11500$ ?

Before solving the problem, rank how difficult do you think it is: (1 being very easy, 5 very hard)

$\begin{array}{lllll}1 & 2 & 3 & 4 & 5\end{array}$

After solving and discussing the problem in class (with the professor and my peer), rank how difficult you find it.

3

4 


\section{APPENDIX C: TARGETED AND GENERAL WORD PROBLEMS}

\section{Part 1: Examples of General Word Problems}

1. A company incurs a $\$ 36550$ loss over a 5- month period. What was the average loss per month?

2. Felicia lives in a town that is 1227 feet above sea level. She visits her sister who lives in a town that is 200 feet below sea level.
a) What is the change in altitude of Felicia when she visits her sister?

b) Is this change positive or negative? Why?

3. A university maintains a student-teacher ratio of 20 to 3. If there are 10120 students enrolled, how many teachers are needed to maintain the ratio?

4. If $5 \frac{1}{2}$ pounds of ground beef is used to 12 hamburgers, how much ground beef is in each hamburger?

\section{Part 2: Examples of Targeted Word Problems}

\section{Health Topics Sample Problems}

Energy expended or calories burned during exercise are influenced by body weight, workout intensity, conditioning level and metabolism. The chart shown calculates calories burned per hour for different body weights. (Source: http://www.nutristrategy.com/activitylist.htm)

\begin{tabular}{l|c|c|c|c}
\hline Exercise \& Calories Burned & $130 \mathrm{lbs}$ & $155 \mathrm{lbs}$ & $180 \mathrm{lbs}$ & $205 \mathrm{lbs}$ \\
\hline Aerobics, general & 384 & 457 & 531 & 605 \\
\hline Aerobics, high impact & 413 & 493 & 572 & 651 \\
\hline Aerobics, low impact & 295 & 352 & 409 & 465 \\
\hline Aerobics, step aerobics & 502 & 598 & 695 & 791 \\
\hline Archery & 207 & 246 & 286 & 326 \\
\hline Backpacking, Hiking with pack & 413 & 493 & 572 & 651 \\
\hline Badminton & 266 & 317 & 368 & 419 \\
\hline Bagging grass, leaves & 236 & 281 & 327 & 372 \\
\hline
\end{tabular}
a) Pick your favorite exercise from the table above.
b) List the calories burned per hour for that exercise for someone who weighs $155 \mathrm{lbs}$.
c) If this person exercises every day for TWO hours, calculate the total number of calories burned after 30 days of exercising.
d) Pick another exercise of your choice. Calculate the same quantity mentioned in $\mathrm{C}$ for someone who weighs $155 \mathrm{lbs}$.
e) Which exercise (of the two you picked) would burn more calories? Estimate how many more calories you'd burned in 30 days by doing the exercise that burns more calories.
f) It is known that in order to lose $1 \mathrm{lb}$ of fat, you need to burn 3500 calories. Convert your answer in e) into lbs. How many more pounds you'd loose if you were to do the workout that burns more?

\section{Finance Topics Sample Problems}

Suppose you bring home $\$ 1500$ after taxes every month. You'd like to buy a new car for $\$ 20000$.

a) Suppose you have $\$ 5000$ in savings. If you wish to put $1 / 2$ of your savings as down payment, and finance the rest, how much money do you need to finance the car?

b) Suppose you get an offer to finance the car over 3 years (36 years) with $0 \%$ interest rate. How much would your monthly payments be?

c) What is the ratio of these monthly payments to your take home pay?

d) Suppose you decided to put all of your savings in down payment. How much would your monthly payment be assuming you finance it as explained in part $b$ ?

e) How much would you save monthly if you were to put all of your savings in down payments? How much would you save yearly? 
Sport Topics Sample Problems

In football, a passing completion is the number of passes that a player successfully completes and is caught by a receiver. The table below was adapted from the NCAA manual (fs.ncaa.org/Docs/stats/Stats_Manuals/Football/2011ez.pdf), read below.

"SAMPLE COMPILATION OF NCAA PASS-EFFICIENCY FORMULA"

Sample Statistics:

Games Played - 9

Pass Attempts - 166

Pass Completions - 98

Yards Passing - 1,567

Touchdown Passes - 16

Interceptions - 7

NOTE: To qualify for national ranking, individuals must average a minimum of 15 pass attempts per game played.

Factor One-Completion Percentage

Pass Completions divided by Pass Attempts times 100

$98 \div 166=.5904 \times 100=59.04$

Factor Two-Yards Per Attempted Pass

Yards Passing divided by Pass Attempts times 8.4

$1,567 \div 166=9.44 \times 8.4=79.30$ "

a) According to http://www.footballstatmanager.com/stat-list.aspx\#PassPct, the passing completion percentage is "The percentage of pass attempt that are successfully completed. This is calculated by dividing the number of completions by the number of passing attempts". Is this definition accurate? If not, how would you get a percentage?

b) How was the completion percentage calculated in the "SAMPLE COMPILATION OF NCAA PASSEFFICIENCY FORMULA"?

c) Convert that percentage to a fraction (in lowest form).

d) Would the completion percentage be different than the one calculated if the number of games played change to 11 ? Explain. 